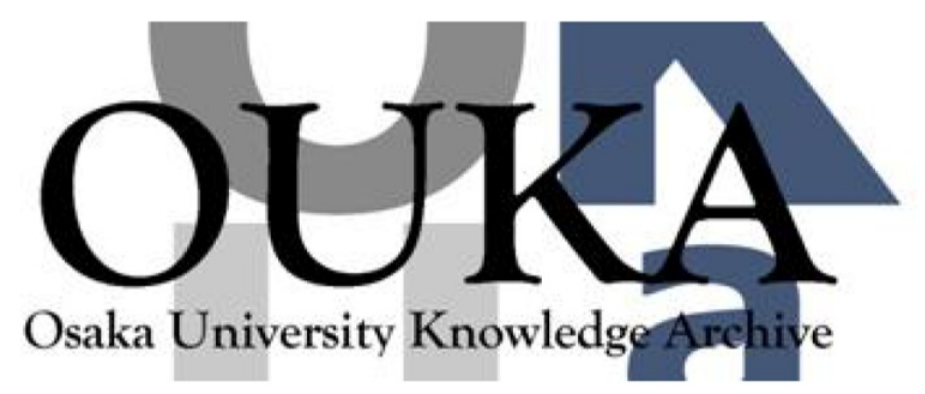

\begin{tabular}{|c|l|}
\hline Title & $\begin{array}{l}\text { Use of imaging plates at near saturation for } \\
\text { high energy density particles }\end{array}$ \\
\hline Author(s) & $\begin{array}{l}\text { Tanimoto, Tsuyoshi; Ohta, Kazuhide; Habara, } \\
\text { Hideaki et al. }\end{array}$ \\
\hline Citation & $\begin{array}{l}\text { Review of Scientific Instruments. 79(10) } \\
\text { p. 10E910-1-p. 10E910-3 }\end{array}$ \\
\hline Issue Date & $2008-01$ \\
\hline oaire:version & VoR \\
\hline URL & https://hdl. handle. net/11094/2967 \\
\hline rights & \\
\hline Note & \\
\hline
\end{tabular}

Osaka University Knowledge Archive : OUKA

https://ir. Library. osaka-u. ac. jp/

Osaka University 


\title{
Use of imaging plates at near saturation for high energy density particles ${ }^{a)}$
}

\author{
Tsuyoshi Tanimoto, ${ }^{1,2}$ Kazuhide Ohta, ${ }^{1,2}$ Hideaki Habara, ${ }^{1,2}$ Toshinori Yabuuchi, ${ }^{3}$ \\ Ryousuke Kodama, ${ }^{1,2}$ Motonobu Tampo, ${ }^{2}$ Jian Zheng, ${ }^{4}$ and Kazuo A. Tanaka ${ }^{1,2}$ \\ ${ }_{1}^{1}$ Graduate School of Engineering, Osaka University, Osaka 565-0871, Japan \\ ${ }^{2}$ Institute of Laser Engineering, Osaka University, Osaka 565-0871, Japan \\ ${ }^{3}$ University of California San Diego, San Diego, California 92093-0417, USA \\ ${ }^{4}$ Department of Modern Physics, University of Science and Technology of China, Hefei, Anhui 230026, \\ People's Republic of China
}

(Presented 13 May 2008; received 12 May 2008; accepted 26 August 2008; published online 31 October 2008)

\begin{abstract}
Since an imaging plate (IP) is sensitive to electron, ion, and x rays, it can be used as a detector for laser plasma experiment using ultraintense laser. Moreover, an IP has the advantageous features such as high sensitivity, wide dynamic range, and high spatial resolution. Even though IP itself has a considerable wide dynamic range up to $10^{5}$, the IP data have appeared often saturated at an IP reading device. We propose a reading technique by inserting optical density filters so that an apparently saturated IP data can be saved. (C) 2008 American Institute of Physics.
\end{abstract}

[DOI: 10.1063/1.2987679]

\section{INTRODUCTION}

In fast ignition in laser fusion, ${ }^{1-4}$ it is significantly important to measure the accelerated high-energy electrons ${ }^{5-9}$ as well as ions ${ }^{10-15}$ and $\mathrm{x}$ rays. ${ }^{16-18}$ Thermoluminescence dosimeters, charge-coupled device cameras, CR-39 detectors, and an $\mathrm{x}$-ray film are now widely used to obtain those signals. Recently, imaging plates (IPs) have been proposed as a new detector and have been used successfully. ${ }^{6-9,16,17}$ The IP has features such as high sensitivity, high spatial resolution, and wide dynamic range with a linear response. However when high flux particles such as hot electrons irradiate IP, the signal appeared saturated when the IP is processed using a reading device. This apparent saturation occurs often when the photomultiplier (PM) in the device is saturated. In order to recover the data from the apparent saturation, it is possible to improve the reading condition of IP in the device. Here we propose a new reading technique by using an optical filter without mechanical reconstruction of the reading device.

\section{EXPERIMENT}

The data processing of a recorded IP utilizes photostimulated luminescence (PSL) phenomenon as shown in Fig. 1. In an IP reading device, the laser light of $633 \mathrm{~nm}$ irradiates the recorded IP. Then, the IP emits the PSL at $390 \mathrm{~nm}$. This light is detected by a PM and is read as an IP signal. The PM saturates often with a strong input signal. In order to avoid saturation, the intensities of both 633 and $390 \mathrm{~nm}$ light could be attenuated. Our new technique in the reading process is to use neutral density (ND) filters. Both irradiating and emitted light intensities are attenuated by ND filters. The attenuation depends on the transmittance of ND filter. The type of optical

\footnotetext{
${ }^{\text {a) }}$ Contributed paper, published as part of the Proceedings of the 17th Topical Conference on High-Temperature Plasma Diagnostics, Albuquerque, New Mexico, May 2008.
}

filter we used is the so-called $10 \%$ transmission filter in a visible light region. The transmittance is confirmed by using a spectrophotometer to be $10.72 \%$ at $633 \mathrm{~nm}$ and $9.81 \%$ at $390 \mathrm{~nm}$, respectively. From this result, the signal intensity could become $1.05 \%$ from the initial intensity by multiplying both transmitted values. The IP and the IP reading device are BAS-SR 2025 (Fuji Film) and BAS-1800 (Fuji Film), respectively. The spatial resolution of IP in this experiment is $200 \mu \mathrm{m} /$ pixel. For the calibration of this technique, the $\beta$ radiation source $\left({ }^{147} \mathrm{Pm}\right)$ is used to irradiate IP for $2,4,6$, and $8 \mathrm{~min}$. Figure 2 shows the signal intensity as a function of the exposure period. The signal intensity represents the integrated value within the area of $\beta$ ray source. The circle and the square dots are the results with and without the ND filters, respectively. Each data point includes the data from

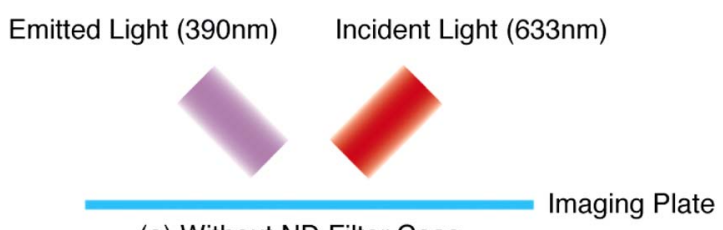

(a) Without ND Filter Case

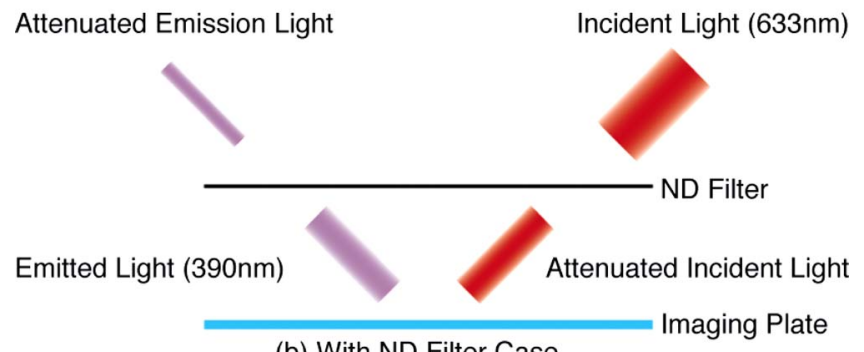

(b) With ND Filter Case

FIG. 1. (Color online) Reading process of IP. (a) and (b) are without and with ND filter cases, respectively. 


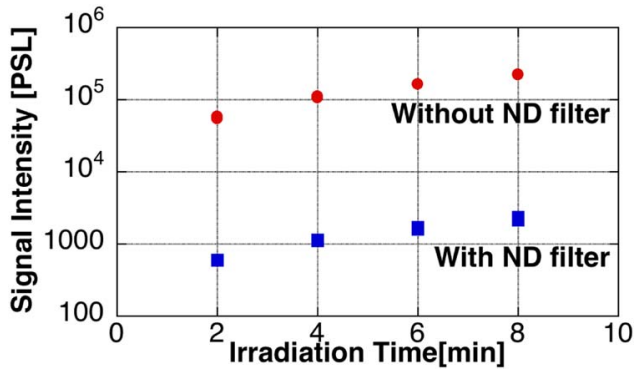

FIG. 2. (Color online) This figure shows the relationship between the irradiation time and the signal intensity. The signal intensity means the integrated value within the area of $\beta$ ray source.

three different shots, which are identical. All the data are reproducible and the two curves are identical within a $0.05 \%$ error with a factor of 100 . Intense data at $10^{5}$ PSL can be transformed clearly into weak data at $10^{3}$ PSL. When we apply this technique to an apparently saturated IP data, we could recover the data by reducing the signal on the PM detector set in the IP reading device.

Figure 3 shows the cases with and without the ND filter when the IP data appears saturated. Figure 3(a) is without ND filter case and shows saturation. Figure 3(b) is with ND filter case and shows the recovered signal by using the ND filter transmittance. The IP signal intensity is saturated at about 1300 (PSL). However, when IP is read by using ND filter the attenuated peak value can be multiplied by 100 as the filter factor, resulting in near 2500 (PSL). In this way, the apparent saturated IP signal can be recovered when the PM is saturated. However, when the IP is saturated the IP should appear saturated no matter what filters are used. This technique is valid only when the PM is saturated.

\section{SUMMARY}

We proposed a new reading process of IP. The irradiating and emitted light intensities were reduced by the ND filter
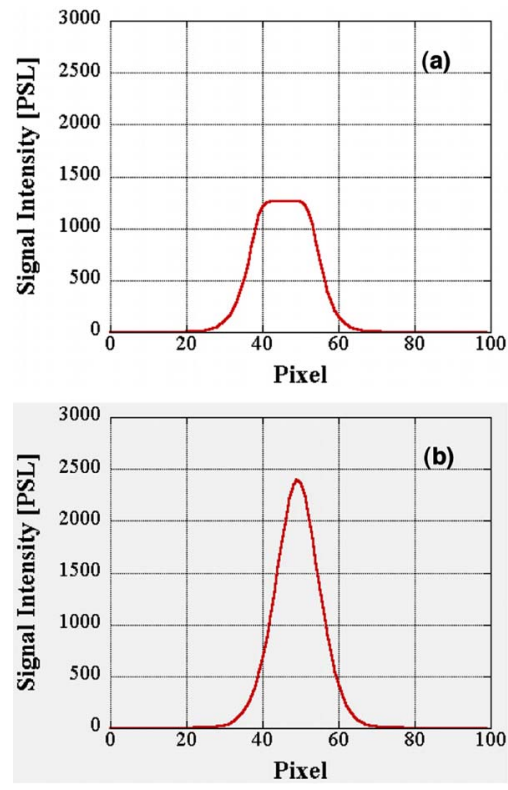

FIG. 3. (Color online) (a) shows the saturated case. (b) is read with the ND filter and is recovered by allowing the transmittance of ND filter. setting in the reading device. We used $1 \%$ attenuation by using a $10 \%$ transmittance filters for both irradiating and emitted light in the IP reading device. To test this technique the IP was exposed to a $\beta$ ray source at four different exposure times. The IP signals were successfully lowered by a factor of 100 using this technique for all the exposure levels. Using this technique we could recover the IP signal when the signal reading is saturated at the PM detector in the reading machine as long as the IP signal is not saturated.

\section{ACKNOWLEDGMENTS}

The authors are thankful for support of the project: Global Center of Excellence (GCOE) at the Department of Electrical, Electric, and Information, the Graduate School of Engineering, Osaka University, Osaka Japan. J. Z. acknowledges the support by Japan-China collaboration program of the core to core university program at National Institute of Fusion Science, Aichi, Japan. This research is supported by a type A grant (No. 19206099) by MEXT.

${ }^{1}$ R. Kodama, P. A. Norreys, K. Mima, A. E. Dangor, R. G. Evans, H. Fujita, Y. Kitagawa, K. Krushelnick, T. Miyakoshi, N. Miyanaga, T. Norimatsu, S. J. Rose, T. Shozaki, K. Shigemori, A. Sunahara, M. Tampo, K. A. Tanaka, T. Toyama, T. Yamanaka, and M. Zepf, Nature (London) 412, 798 (2001).

${ }^{2}$ R. Kodama, H. Shiraga, K. Shigemori, Y. Toyama, S. Fujioka, H. Azechi, H. Fujita, H. Habara, T. Hall, Y. Izawa, T. Jitsuno, Y. Kitagawa, K. M. Krusheinick, K. L. Lancaster, K. Mima, K. Nagai, M. Nakai, H. Nishimura, T. Notimatsu, P. A. Norreys, S. Sakabe, K. A. Tanake, A. Youssef, M. Zepf, and T. Yamanaka, Nature (London) 418, 933 (2002).

${ }^{3}$ M. Tabak, J. Hammer, M. E. Glinsky, W. L. Kruer, S. C. Wilks, J. Woodworth, E. M. Campbell, M. D. Perry, and R. J. Mason, Phys. Plasmas 1, 1626 (1994).

${ }^{4}$ M. Roth, T. E. Cowan, M. H. Key, S. P. Hatchett, C. Brown, W. Fountain, J. Johnson, D. M. Pennington, R. A. Snavely, S. C. Wilks, K. Yasuike, H. Ruh, F. Pegoraro, S. V. Bulanov, E. M. Campbell, M. D. Perry, and H. Powell, Phys. Rev. Lett. 86, 436 (2001).

${ }^{5}$ R. Kodama, Y. Sentoku, Z. L. Chen, G. R. Kumar, S. P. Hatchett, Y. Toyama, T. E. Cowan, R. R. Freeman, J. Fuchs, Y. Izawa, M. H. Key, Y. Kitagawa, K. Kondo, T. Matsuoka, H. Nakamura, M. Nakatsutsumi, P. A. Norreys, T. Norimatsu, R. A. Snavely, R. B. Stephens, M. Tampo, K. A. Tanaka, and T. Yabuuchi, Nature (London) 432, 1005 (2004).

${ }^{6}$ K. A. Tanaka, T. Yabuuchi, T. Sato, R. Kodama, Y. Kitagawa, T. Takahashi, T. Ikeda, Y. Honda, and S. Okuda, Rev. Sci. Instrum. 76, 013507 (2005).

${ }^{7}$ A. L. Lei, K. A. Tanaka, R. Kodama, G. R. Kumar, K. Nagai, T. Norimatsu, T. Yabuuchi, and K. Mima, Phys. Rev. Lett. 96, 255006 (2006).

${ }^{8}$ T. Yabuuchi, K. Adumi, H. Habara, R. Kodama, K. Kondo, T. Tanimoto, K. A. Tanaka, Y. Sentoku, T. Matsuoka, Z. L. Chen, M. Tampo, A. L. Lei, and K. Mima, Phys. Plasmas 14, 040706 (2007).

${ }^{9}$ T. Tanimoto, A. L. Lei, T. Yabuuchi, H. Habara, K. Kondo, R. Kodama, K. Mima, and K. A. Tanaka, J. Phys.: Conf. Ser. 112, 022095 (2008).

${ }^{10}$ S. Gaillard, J. Fuchs, N. Renard-Le Galloudec, and T. E. Cowan, Rev. Sci. Instrum. 78, 013304 (2007).

${ }^{11}$ R. A. Snavely, M. H. Key, S. P. Hatchett, T. E. Cowan, M. Roth, T. W. Phillips, M. A. Stoyer, E. A. Henry, T. C. Sangster, M. S. Singh, S. C. Wilks, A. MacKinnon, A. Offenberger, D. M. Pennington, K. Yasuike, A. B. Langdon, B. F. Lasinski, J. Johnson, M. D. Perry, and E. M. Campbell, Phys. Rev. Lett. 85, 2945 (2000).

${ }^{12}$ A. Maksimchuk, S. Gu, K. Flippo, D. Umstadter, and V. Yu. Bychenkov, Phys. Rev. Lett. 84, 4108 (2000).

${ }^{13}$ E. L. Clark, K. Krushelnick, J. R. Davies, M. Zepf, M. Tatarakis, F. N. Beg, A. Machacek, P. A. Norreys, M. I. K. Santala, I. Watts, and A. E. Dangor, Phys. Rev. Lett. 84, 670 (2000).

${ }^{14}$ S. Gaillard, J. Fuchs, N. Renard-LeGalloudec, and T. E. Cowan, Phys. Rev. Lett. 96, 249201 (2006).

${ }^{15}$ E. L. Clark, K. Krushelnick, M. Zepf, M. Tatarakis, F. N. Beg, P. A. 
Norreys, and A. E. Dangor, Phys. Rev. Lett. 96, 249202 (2001).

${ }^{16}$ S. Fujioka, H. Shiraga, M. Nishikino, M. Heya, K. Shigemori, M. Nakai, H. Azechi, S. Nakai, and T. Yamanaka, Rev. Sci. Instrum. 73, 2588 (2002).

${ }^{17}$ J. S. Green, V. M. Ovchinnikov, R. G. Evans, K. U. Akli, H. Azechi, F. N. Beg, C. Bellei, R. R. Freeman, H. Habara, R. Heathcote, M. H. Key, J. A.
King, K. L. Lancaster, N. C. Lopes, T. Ma, A. J. MacKinnon, K. Markey, A. McPhee, Z. Najmudin, P. Nilson, R. Onofrei, R. Stephens, K. Takeda, K. A. Tanaka, W. Theobald, T. Tanimoto, J. Waugh, L. Van Woerkom, N. C. Woolsey, M. Zepf, J. R. Davies, and P. A. Norreys, Phys. Rev. Lett. 100, 015003 (2008).

${ }^{18}$ S. G. Gales and C. D. Bentley, Rev. Sci. Instrum. 75, 4001 (2004). 